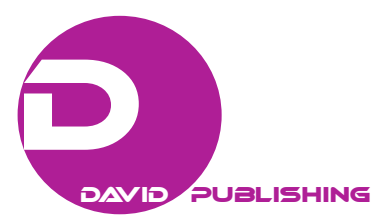

\title{
The Use of Acoustic Quality Assessment in the Management of the Road Noise Reduction Project*
}

\author{
Waldemar Paszkowski \\ Silesian University of Technology, Zabrze, Poland
}

\begin{abstract}
The article presents a new approach to the tasks of noise assessment and reduction in the urbanized environment endangered by road noise sources. It was proposed to include the acoustic quality model in the currently applied quantitative noise assessment in the management of urbanized environment. In particular, this model takes into account subjective features of sound quality, i.e.: loudness, sharpness, roughness, and fluctuation strength as well as noise annoyance assessment obtained in laboratory conditions. The proposed way can be used in estimating investment costs of an acoustic barrier at the design stage.
\end{abstract}

Keywords: acoustic barrier, acoustic quality, noise management, noise reduction, urban areas

\section{Introduction}

Noise management in urban areas involves tasks of creating the acoustic climate. The completion of these tasks usually results in implementing solutions to reduce or minimize the noise based on quantitative assessment. Depending on the needs, these tasks can focus directly on noise reduction i.e. source noise emission, acoustic energy transmission via its propagation, emission to specific areas in the environment. Taking the above into consideration, a noise reduction solution for the needs of acoustic climate creation must be chosen on the basis of assessing the state of noise pollution. According to the existing legal regulations (Minister of the Environment, 2012) quantitative assessment is commonly used to evaluate the threat of noise pollution caused by noise sources.

Research into noise assessment shows the importance of subjective acoustic sensations in sound perception (Fastl \& Zwicker, 2007). This means that the assessment of noise annoyance differs among recipients. Taking the above into consideration, the author of the paper is of the opinion that the quantitative environmental noise pollution assessment is insufficient and does not take the aspects of subjective assessment into account.

The aim of the undertaken research is to present a quantitative and qualitative approach to assessing noise pollution in urban areas with special emphasis placed on incorporating the aspects of acoustic quality into the process of designing an acoustic barrier.

\footnotetext{
${ }^{*}$ The paper is the result of statutory research carried out at the Institute of Production Engineering at the Faculty of Organization and Management of the Silesian University of Technology as part of a project number 13/030/BK_18/0039 called "Development of intelligent production methods as well as work and life environments in the context of production engineering challenges". Waldemar Paszkowski, Ph.D. Eng, Institute Engineering of Production, Silesian University of Technology, Zabrze, Poland. Correspondence concerning this article should be addressed to Waldemar Paszkowski, ul. Roosevelta 26-28, Zabrze 41-800, Poland.
} 


\section{Elements of Noise Management in Urban Areas}

When dealing with problems of noise management, apart from the technical side of this process many "non-technical" aspects in the areas listed below must be addressed as well: strategy, structures, activities, and culture (Figure 1). In a general approach to environmental noise management resources in the area of structures are very important. Depending on the adopted strategy relevant resources are used in decision making. The presented model (Figure 1) assumes the use of particular elements of technical and administrative structures in a given task. In particular, for the presented elements of the structures including the task of noise management the following subsystems can be distinguished: organisation, information, and decision-making (Paszkowski, 2016).

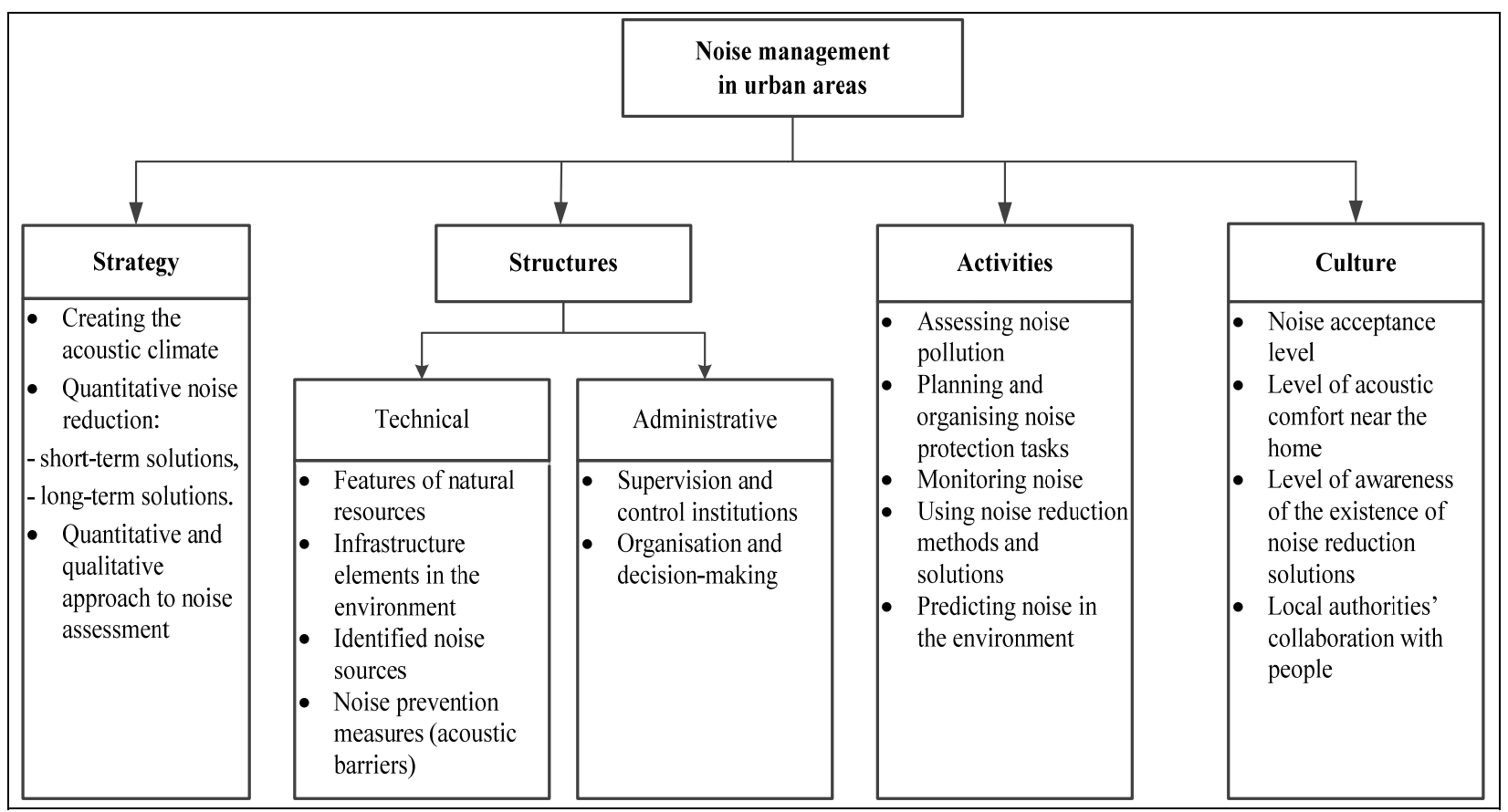

Figure 1. Model of areas and elements of noise management in the environment. Source: Own study based on Kaźmierczak (2000).

A strategy consisting in defining a set of guidelines, restrictions, and criteria should be considered as a key area in environmental noise reduction tasks. In the currently applied approach strategies of noise management in urban areas can be distinguished based on quantitative noise assessment made through:

- Using legal or planning solutions connected with restricting land use and function;

- Implementing organisational or technical noise reduction solutions or a combination of both.

In the first case the strategy is comprehensive and constitutes one of four areas of noise management which complement one another. In comparison, the second approach involves certain functional, spatial, and economic restrictions and is also more concerned with local conditions. Apart from the restrictions mentioned above, possible solutions used in noise reduction are most frequently ones which reduce noise as it propagates along the source - propagation path-receiver system. Research into the subjective significance of noise assessment indicates that qualitative sound assessment measures should be taken into account (Fastl \& Zwicker, 2007; Preis \& Kaczmarek, 2010). The results of the author's own research in this area (Kaźmierczak, 2008) justify the need of elaborating a quantitative and qualitative noise assessment model. An important problem 
which remains to be solved is finding a relationship between the quantitative and qualitative noise assessment. Taking the above into consideration, such a model can constitute a new approach to the strategy of noise management in urban areas. This approach includes acoustic sensations present when perceiving noise. It can be assumed that the quantitative and qualitative noise assessment method will result in adopting solutions in environmental noise management different from those in use now. In some cases these can be solutions limited only to creating acoustic sensations through propagation (e.g. through masking noise sources); in other cases the proposed method may include solutions where noise will be reduced directly in places with sound emission.

\section{Selected Aspects of Perceiving Sound in the Environment}

Research into the qualitative approach to assessing the environment at risk of noise pollution among others point to the importance of sound quality measures expressing subjective sensations of receiving acoustic signals (Fastl \& Zwicker, 2007). The analysis of sound phenomena can be considered in three dimensions, as (Augoyard, 1978):

- A physical signal (which can be measured quantitatively);

- The actual sound (listened to and interpreted through perception);

- A represented sound (in relation to cultural and group contexts).

Decisions in the environment can be made through (Vogiatzis \& Remy, 2014):

- An environment diagnosis, the main aim of which is to implement solutions or noise protection measures for sound parameters measured in the environment;

- Environment management, characterized by offensive activities and aiming to consolidate a place with a sound for a given urban area. Such activity may also include tasks of informing the residents of acoustic comfort and managing sites of acoustic conflict;

- Soundscape design as a new perspective with a cultural and aesthetic character, consisting in undertaking necessary activities aimed at stimulating the awareness of acoustic space and at developing the awareness with recorded urban sounds, which undoubtedly enhances the quality of sound.

Brown, Jian, and Truis (2011) describe a soundscape as a way of perceiving the acoustic environment and as understood by a person, group, or society. It generally specifies a set of perceived sounds of natural and anthropogenic origin, always connected with the context of time, place, and activity. Research into a soundscape often refers to the acoustic environment, in which the effect of the impact of sounds has a positive influence on well-being, health, or on what a person is doing.

Publications on this topic focus mainly on preferred sounds (Brown, 2011). This article is concerned with the issue of acoustic quality of urban areas threatened by noise sources. The proposed notion of acoustic quality is understood as a perceived disturbance of the environment caused by the impact of anthropogenic noise sources. It assumes that the assessment of acoustic quality will be connected with the time, with the place where people who can be affected by the noise sources mentioned above are and the kind of activity they are involved in. In this understanding the assessment of acoustic quality of urban areas can be expressed as a measure/degree of its reduction. This notion is different from the meaning of a soundscape and can constitute a new approach in the strategy of noise management in urban areas.

\section{Modeling the Acoustic Quality of Urban Areas}

In the field of acoustic quality assessment, research was carried out using advanced data processing 
methods (Paszkowski \& Loska, 2017a; Paszkowski \& Loska, 2017b; Paszkowski \& Dąbrowski, 2017; Kosicka, Kozłowski, \& Mazurkiewicz, 2015).

In the author's own research an assumption was made that the assessment of acoustic quality of urban areas at risk of noise pollution will be determined using the elaborated model (Figure 2). It was assumed that the input data for the model will be:

- Sound emission points;

- Cidentified characteristics of structures: imaging of the topography, buildings, and infrastructure;

- RECORD of acoustic signals in specific sound emission points.

It was assumed that the model of acoustic quality of the analyzed area will consist of:

- A model of the properties and characteristics of the structures;

- A model of noise annoyance using psychophysical measures of sound and the results of research into noise annoyance in laboratory conditions.

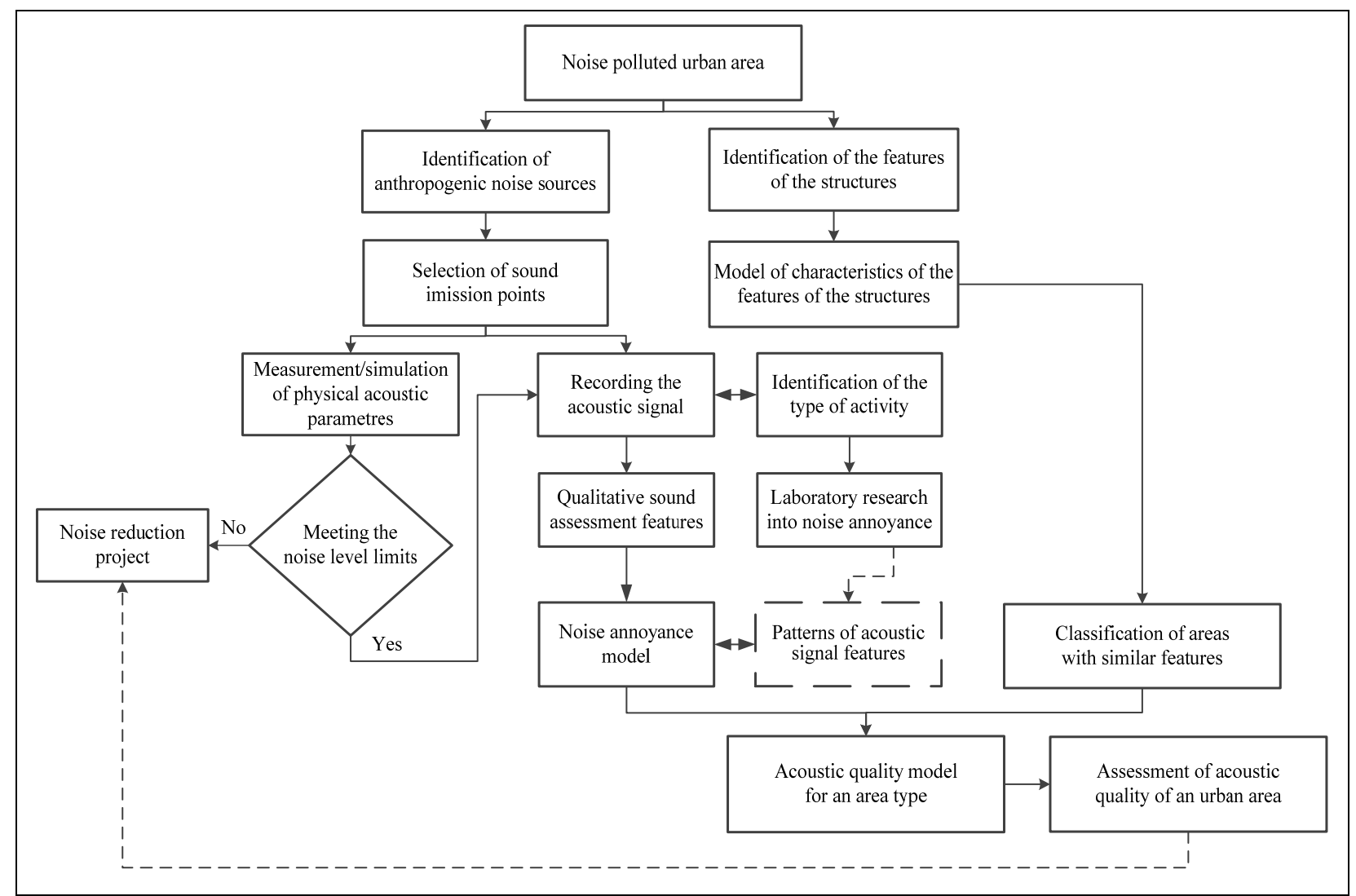

Figure 2. Scheme of modelling the acoustic quality of the urban areas. Source: Own study.

To find the final form of the model of an area's acoustic quality it will be necessary to relate noise annoyance with the assessment of the features of similar structures.

\section{A Proposal to Use Acoustic Quality in Designing Acoustic Barriers}

According to the directive in force (European Parliament, 2002) the present environmental noise reduction strategy makes use of the quantitative approach to noise pollution assessment. It usually consists in reducing the level of noise above the allowed limit to the allowed value depending on the type of source, time of day or 
night, and the type of area. For this purpose, to follow a long-term noise protection policy the allowed noise levels in the environment expressed by indexes $\mathrm{L}_{\text {Den }}$, are used for day-evening-night and night respectively (Minister of the Environment, 2012). At this moment the choice of an appropriate long-term noise reduction solution depends on determining how much the long-term noise level limits were exceeded based on acoustic measurements or sound level simulations.

The proposed quantitative and qualitative method of assessing noise in urban environment in the noise management strategy (Figure 1) and in acoustic quality modeling (Figure 2) introduce a novel approach to noise reduction. This approach changes the existing method and introduces the assessment of acoustic quality. Including psychophysical aspects of sound in acoustic quality assessment leads to noise reduction tasks being focused on assessing the sensations of sound perception when evaluating sound level.

A typical and commonly used road noise reduction measure is an acoustic barrier. Acoustic barriers (artificial structures) are usually a series of artificial elements situated along transport routes and for this reason are treated as developments which are incorporated into the natural landscape. The tasks of designing acoustic barriers are carried out on the basis of the requirements and assessment in these areas:

- Acoustic: system (source-barrier-observer) geometry assessment, acoustic effectiveness, acoustic insulation, absorption index;

- Technical: structural characteristics (geometry, material), transparency of the barrier, aesthetics;

- Economic: investment costs (e.g.: expert opinion and documentation, purchase of materials and production, assembly), operating costs (e.g.: replacing any losses of materials, removing the effects of vandalism, removing snow);

- Operational: weather resistance (corrosion, UV radiation), cleaning and maintenance, fire resistance.

The inclusion of acoustic quality assessment in designing acoustic barriers results in obtaining additional information regarding the perception and sensations of sound imission, which de facto extend the existing method. Choosing the right design solution should be preceded by variant analysis, taking the assessment of sound quality features into consideration.

\section{An Example of Estimating Investment Costs of an Acoustic Barrier Using Quantitative and Qualitative Acoustic Features}

The investment cost of an acoustic barrier can be estimated at the design stage using the DGC index. This index can be used to estimate the technical cost of achieving a desired ecological effect and is equal to a price, which makes it possible to obtain a discounted income equal to discounted costs, which renders the undertaking cost-effective. In the proposed approach the ecological effect can refer to places polluted with noise and can be expressed by means of sound assessment features and noise annoyance assessment in relation to the cost of the investment project (Rączka, 2003):

$$
D G C=\frac{\sum_{t=0}^{t=n} \frac{I C_{t}+O C_{t}}{(1+i)^{t}}}{\sum_{t=0}^{t=n} \frac{E E_{t}}{(1+i)^{t}}}
$$

where:

$I C_{t}$-investment costs in a given year; 
$O C_{t}$-operational costs in a given year;

$i$ - the discount rate;

$t$-year of incurring costs in the years of the installation's functioning;

$E E_{t}-\mathrm{a}$ measure of the ecological effect achieved in respective years (ecological effect) with the assumption that the price does not change in the whole period of analysis.

The key element of working out the $D G C$ index is determining the value of $E E_{t}$. In the proposed approach it is assumed that selected features of recorded acoustic signals in analysed points in the environment will be the source of obtaining data necessary to determine the value of $E E_{t}$. It was assumed that these will be the following features (Table 1):

- Average long-term sound level indexes $\mathrm{L}_{\text {Den }}, \mathrm{L}_{\mathrm{Night}}$, determined for 24 hours;

- Sound quality features: loudness $\left(\mathrm{N}_{5}-95\right.$ percentile loudness), roughness (R), sharpness (S), fluctuation strength (FS) in relation to $\mathrm{L}_{\mathrm{Aeq}}, \mathrm{L}_{\mathrm{AeqN}}$ (Minister of the Environment, 2012), i.e. equal sound levels;

- A mean noise annoyance assessment determined in laboratory tests, in relation to $\mathrm{L}_{\mathrm{AeqD}}$ and $\mathrm{L}_{\mathrm{AeqN}}$, based on the registered acoustic signals.

The investment cost was assessed for Project A and Project B taking into consideration selected features of acoustic signals (Table 1). The mean noise annoyance assessment was obtained when emitting in laboratory conditions recorded acoustic signals for the day and the night. The research was conducted on 80 persons between 20 and 60 years of age. The acoustic signals (six signals) were calibrated to $\mathrm{L}_{\mathrm{AeqD}}$ and $\mathrm{L}_{\mathrm{AeqN}}$ classes and represented random road traffic acoustic events 10 seconds in duration. Each signal was assessed in a one to five scale where one described the signal's annoyance assessment as "unbearable".

Table 1

Values of Selected Features to Assess the Ecological Effect

\begin{tabular}{lll}
\hline Feature type & Project A & Project B \\
\hline $\mathrm{L}_{\text {Den }}(\mathrm{dB})$ & 66.42 & 62.31 \\
$\mathrm{~L}_{\mathrm{Night}}(\mathrm{dB})$ & 59.84 & 58.74 \\
$\mathrm{~N}_{5}$ (sone) & 2.03 & 11.17 \\
$\mathrm{R}$ (asper) & 1.48 & 1.69 \\
$\mathrm{~S}$ (acum) & 1.00 & 1.39 \\
$\mathrm{FS}$ (vacil) & 0.41 & 0.97 \\
Average noise annoyance assessment (ANAS) & 1.92 & 1.61 \\
Sum of features $(\mathrm{Z})$ & 133.10 & 137.88 \\
Estimated unit cost of an acoustic barrier (ECU) $\left(\mathrm{PLN} / \mathrm{m}^{2}\right)$ & 800 & 800 \\
\hline
\end{tabular}

The acoustic signal features used represent a quantitative and qualitative assessment of a sound signal. The relationship between the quantitative and qualitative features is expressed by means of adding their values, i.e.:

$$
Z=L_{\text {Den }}+L_{\text {Night }}+N_{5}+R+S+F S+A N A S
$$

Then, in order to determine the $E E_{t}$ the following relationship between values is proposed:

$$
E E_{t}=\frac{A N A S}{Z} \cdot E C U
$$

The example analyzed here is hypothetical, its aim is to present a method of calculating the DGC index. The following assumptions of input data were used for Project A and Project B (Table 2): 
- Investment outlays in year 0 ;

- A constant operating cost (without depreciation) in the planned five years of the acoustic barrier's "life";

- A constant estimated unit cost of an acoustic barrier;

- The value of $E E_{t}$ does not change in the analyzed period, which means that unchanging acoustic conditions were assumed for the entire period of the barrier's "life";

- The discount rate in the analyzed period is $8 \%$.

Table 2

Input Data Used to Determine the DGC Index

\begin{tabular}{|c|c|c|c|c|c|c|c|c|c|c|c|c|}
\hline \multirow{2}{*}{ Input data } & \multicolumn{6}{|c|}{ Project A } & \multicolumn{6}{|c|}{ Project B } \\
\hline & 0 & 1 & 2 & 3 & 4 & 5 & 0 & 1 & 2 & 3 & 4 & 5 \\
\hline Investment outlays (thousand PLN) & 80 & 0 & 0 & 0 & 0 & 0 & 80 & 0 & 0 & 0 & 0 & 0 \\
\hline $\begin{array}{l}\text { Operating costs (without depreciation) } \\
\text { (thousand PLN) }\end{array}$ & 0 & 30 & 30 & 30 & 30 & 30 & 0 & 30 & 30 & 30 & 30 & 30 \\
\hline$E E_{t}\left(\right.$ noise assessment $\left(\mathrm{PLN} / \mathrm{m}^{2}\right)$ & 0 & 11.54 & 11.54 & 11.54 & 11.54 & 11.54 & 0 & 9.34 & 9.34 & 9.34 & 9.34 & 9.34 \\
\hline Discount indexes $(r=8 \%)$ & 1 & 0.926 & 0.857 & 0.794 & 0.735 & 0.681 & 1 & 0.926 & 0.857 & 0.794 & 0.735 & 0.681 \\
\hline
\end{tabular}

After putting the relevant data from Tables 1 and 2 into Equation (1) we obtain the final values of the $D G C$ index:

- For Project A: $D G C=30.59\left(\mathrm{PLN} / \mathrm{m}^{2}\right)$

- For Project B: $D G C=37.80\left(\mathrm{PLN} / \mathrm{m}^{2}\right)$

After comparing the DGC indexes for the analyzed Projects A and B it can be seen that the dynamic unit cost of an acoustic barrier is significantly higher in the case of Project B. At the same time, on the basis of the input data used for the calculations it can be said that the sum of features $(Z)$ in Table 1 is bigger for Project $B$.

\section{Conclusions}

On the basis of the presented model of areas and elements of noise management in the environment a new, qualitative approach to the strategy of managing noise in urban areas was proposed. The systemic approach to noise assessment presented in this article and consequently an effective method of managing noise in the environment requires integrated and coordinated activities in these areas: acoustic, technical, social, organizational, and economic.

The presented model of acoustic quality of urban areas includes noise annoyance assessment and the assessment of the features of similar structures in the environment. On the basis of the proposed model it was suggested that the measure of the ecological effect should be included in the process of designing acoustic barriers. It was suggested that in order to assess the investment cost of an acoustic barrier the DGC index taking the acoustic quality model into account should be used.

In the author's opinion using the predicted measure of the ecological effect at the stage of designing an acoustic barrier may improve the effectiveness of noise management solutions in urban areas. To improve the presented calculation method further research will be focused on determining the dynamic change in time of $E E_{t}$. 


\section{References}

Augoyard, J. F. (1978). Les pratiques d'habiter a travers les phenomenes sonore-contribution a une critique de l'habitat. Paris, Ecole Speciale d'Architecture.

Brown, A. L. (2011). Soundscapes and soundscape planning. In Conference proceedings ICSV18, Rio de Janeiro, 2-4 November.

Brown, A. L., Jian, J., \& Truis, G. (2011). Towards standardization in soundscape preference assessment. Applied Acoustics, $72(6), 387-392$.

Directive 2002/49/EC of the European Parliament and of the Council of relating to the assessment and management of environmental noise. Official Journal L 189 (25 June 2002).

Fastl, H., \& Zwicker, E. (2007). Psychoacoustics, facts and models. Berlin: Springer Verlag.

Kaźmierczak, J. (2000). Operating technical systems. Gliwice, Silesian University of Technology.

Kaźmierczak, J., (ed.). (2008). Handbook for self-government workers participating in creating and using strategic acoustic maps. Katowice, Central Mining Institute.

Kosicka, E., \& Kozłowski, E., \& Mazurkiewicz, D. (2015). The use of stationary tests for analysis of monitored residual processes. Eksploatacja i Niezawodnosc-Maintenance and Reliability, 17(4), 604-609.

Minister of the Environment. (2012). Regulation of the Minister of the Environment of amending the regulation on allowable noise levels in the environment. Journal of Laws, item 1109 (1 October 2012).

Paszkowski, W. (2016). Assessment of noise source threat in special economic and idustrial zones. In Milewska, E. (ed.), Support systems in production engineering. Technical systems engineering, 2(14), 270-275.

Paszkowski, W., \& Loska, A. (2017a). The use of neural network model in the assessment of annoyance of the industrial noise sources. In Burduk A., \&Mazurkiewicz D. (eds.), Intelligent systems in production engineering and maintenance-ISPEM. Advances in Intelligent Systems and Computing, 637, 428-439.

Paszkowski, W., \& Loska, A. (2017b). The use of data mining methods for the psychoacoustic assessment of noise in urban environment. In Proceedings of 17th International Multidisciplinary Scientific GeoConference: Ecology, Economics, Education and Legislation. Ecology and Environmental Protection, 17(52), 1059-1066.

Paszkowski, W., \& Dąbrowski, M. (2017). The use of acoustic maps in modeling features of objects oriented on acoustic quality of the environment. In Proceedings of 17th International Multidisciplinary Scientific GeoConference. Informatics, geoinformatics and remote sensing. Cartograhy and GIS, 17(23), 769-776.

Preis, A., \& Kaczmarek, T. (2010). Annoyance of time-varying road-traffic noise. Archives of acoustics, 35(3), 383-393.

Raczka, J. (2003). The cost-effectiveness analysis-A superior alternative to the cost-benefit analysis of environmental infrastructure investments. In Fifth European Conference on Evaluation of the Structural Funds “Challenges for Evaluation in an Enlarged Europe”, Budapest, 10-13 June.

Vogiatzis, K., \& Remy, N. (2014). From environmental noise abatement to soundscape creation through strategic noise mapping in medium urban agglomerations in South Europe. Science of the Total Environment, 482-483, 420-431. 